Article

\title{
Dysprosium Removal from Water Using Active Carbons Obtained from Spent Coffee Ground
}

\author{
Lorena Alcaraz ${ }^{1}{ }^{\circledR}$, María Esther Escudero ${ }^{1}$, Francisco José Alguacil ${ }^{1}$, Irene Llorente ${ }^{1}$, \\ Ana Urbieta ${ }^{2}$, Paloma Fernández ${ }^{2}$ and Félix Antonio López ${ }^{1, *(1)}$ \\ 1 National Center for Metallurgical Research (CENIM), Spanish National Research Council (CSIC), Avda. \\ Gregorio del Amo, 8, 28040 Madrid, Spain; alcaraz@cenim.csic.es (L.A.); mevaquero@cenim.csic.es (M.E.E.); \\ falgua@cenim.csic.es (F.J.A.); irene@cenim.csic.es (I.L.) \\ 2 Department of Materials Physics, Faculty of Physics, Complutense University of Madrid, s/n, 28040 Madrid, \\ Spain; anaur@fis.ucm.es (A.U.); arana@ucm.es (P.F.) \\ * Correspondence: f.lopez@csic.es
}

Received: 5 August 2019; Accepted: 19 September 2019; Published: 25 September 2019

check for updates

\begin{abstract}
This paper describes the physicochemical study of the adsorption of dysprosium $\left(\mathrm{Dy}^{3+}\right)$ in aqueous solution onto two types of activated carbons synthesized from spent coffee ground. Potassium hydroxide $(\mathrm{KOH})$-activated carbon is a microporous material with a specific Brunauer-Emmett-Teller (BET) surface area of $2330 \mathrm{~m}^{2} \cdot \mathrm{g}^{-1}$ and pores with a diameter of $3.2 \mathrm{~nm}$. Carbon activated with water vapor and $\mathrm{N}_{2}$ is a solid mesoporous, with pores of $5.7 \mathrm{~nm}$ in diameter and a specific surface of $982 \mathrm{~m}^{2} \cdot \mathrm{g}^{-1}$. A significant dependence of the adsorption capacity on the solution $\mathrm{pH}$ was found, but it does not significantly depend on the dysprosium concentration nor on the temperature. A maximum adsorption capacity of $31.26 \mathrm{mg} \cdot \mathrm{g}^{-1}$ and $33.52 \mathrm{mg} \cdot \mathrm{g}^{-1}$ for the chemically and physically activated carbons, respectively, were found. In both cases, the results obtained from adsorption isotherms and kinetic study were better a fit to the Langmuir model and pseudo-second-order kinetics. In addition, thermodynamic results indicate that dysprosium adsorption onto both activated carbons is an exothermic, spontaneous, and favorable process.
\end{abstract}

Keywords: dysprosium; activated carbon; spent coffee ground; adsorption

\section{Introduction}

Nowadays, rare earths (REE) are becoming increasingly interesting due to their essential role in several applications such as permanent magnets, phosphor lamps, rechargeable NiMH batteries, and catalysts, among others [1]. The increasing popularity of hybrid and electric cars, wind turbines, and compact fluorescent lamps is causing an increase in the demand and price of REEs since several compounds of REE, such as neodymium and dysprosium [2], are in smart-batteries that power every electric and hybrid-electric vehicle [3]. In 2010, the European Commission in the report Critical Raw Materials for the European Union considered REEs as the most critical raw materials group. Among them, neodymium $(\mathrm{Nd})$, europium $(\mathrm{Eu})$, terbium $(\mathrm{Tb})$, dysprosium $(\mathrm{Dy})$, and yttrium $(\mathrm{Y})$ were considered the five most critical REEs [1]. It is expected that the demand for $\mathrm{Nd}$ and Dy will rise by $700 \%$ and $2600 \%$ over the next 25 years, respectively [4].

On the other hand, technological development has increased the dumping of electronic waste, which is facilitating the release of significant quantities of these elements along with several other toxic elements into subsoils and groundwater [3]. Hence, the investigation on different adsorption processes is fully pertinent. To the best of our knowledge, maximum acceptable limits for REE in drinking water are not available from any international health organization, nor is sufficient data about their toxicity to human health. However, contamination of the environment by different kinds of toxic species is one 
of the most serious problems today. Thus, the REE group represents important elements found in the environment and need to be studied at greater depth to understand their effects on human health, and the removal or recovery options from the environment should be deeply investigated [3].

Among the different methods to eliminate contaminants, adsorption onto different carbonaceous materials is an efficient option because of its simplicity and cost-effectiveness [5,6]. Nowadays, the most commonly adopted adsorbent to remove pollutants from water is activated carbon, which is characterized by its high porosity, great surface area, and high degree of surface reactivity [7]. In this sense, the obtention of activated carbons from renewable and cheaper precursors is catching increasing attention from the researchers [7]. Several investigations have been developed about the use of biomass as a precursor, such as residues derived from tea $[8,9]$, coffee $[10,11]$, winemaking waste $[12,13]$, and olives bones [14,15], in order to obtain activated carbon.

In the present work, we obtained activated carbons from spent coffee waste. These activated carbons were both physically and chemically activated. Characterization of both activated carbons and their capacity of dysprosium adsorption were assessed.

\section{Materials and Methods}

\subsection{Synthesis of the Activated Carbons}

Coffee waste recovered from the beverage preparation (spent coffee ground, SCG) were provided by the commercial canteen. The coffee ground used was a mixture $10(\mathrm{wt} \%)$ roasted and $90(\mathrm{wt} \%)$ natural.

SCG were subjected to a hydroalcoholic process in an extraction medium $\left(\mathrm{EtOH}: \mathrm{H}_{2} \mathrm{O}, v / v\right)$ 50:50 at $393 \mathrm{~K}$ for $30 \mathrm{~min}$ in order to obtain the corresponding precursor. Finally, the precursor obtained was turned into activated carbon by both chemical and physical processes.

\section{Chemical Activation}

To perform the chemical activation, $1 \mathrm{~g}$ of the precursor was mixed with $1.5 \mathrm{~g}$ of potassium hydroxide $(\mathrm{KOH})$. The homogenized mixtures were placed in alumina crucibles and treated in a Carbolite STF 15 tubular oven (Carbolite Gero, Neuhausen, Germany) at $1123 \mathrm{~K}$ for 30 min under a nitrogen carrier $\left(150 \mathrm{~mL} \cdot \mathrm{min}^{-1}\right)$. After cooling down to room temperature, the black solid obtained was washed several times with Milli-Q water until neutral $\mathrm{pH}$ was achieved. The obtained sample was named AC-CA.

\section{Physical Activation}

The physical activation of the precursor was carried out in a quartz reactor at $1073 \mathrm{~K}$ for $120 \mathrm{~min}$. Approximately $20 \mathrm{~g}$ of precursor was added into the reactor. $\mathrm{N}_{2}$ with a flow rate of $0.5 \mathrm{~mL} \cdot \mathrm{min}^{-1}$ was pumped into the reactor throughout the activation to act as gas carrier during the heating ramp. When the treatment temperature was achieved, deionized water was introduced in the reactor by means of a peristaltic pump with a similar flow rate, hence changing from $\mathrm{N}_{2}$ to $\mathrm{H}_{2} \mathrm{O}$. The obtained sample was named AC-PA.

\subsection{Characterization of the Activated Carbons}

The porous structure of the activated carbons was characterized by $\mathrm{N}_{2}$ adsorption at $77 \mathrm{~K}$ using an Accelerated Surface Area and Porosimetry System (Micromeritics Instruments Corp, Norcross, GA, USA). The samples were partially degassed at $623 \mathrm{~K}$ for $16 \mathrm{~h}$. The specific surface was determined by analyzing the adsorption isotherm via the BET (Brunauer-Emmett-Teller) equation and density functional theory (DFT) models, employing Micromeritics and Quantachrome software (ASAP2020 V03.04, Norcross, GA, USA).

The surface of the activated carbons was examined by field emission scanning electron microscope (FE-SEM,) using a Hitachi S 4800 J microscope (Tokyo, Japan). 
Raman experiments and $\mu$-Photoluminescence $(\mu$-PL) were performed at room temperature in a Horiba Jovin Yvon LabRAM HR800 confocal microscope (Horiba, Kyoto, Japan). A He-Cd laser $\left(\lambda_{\text {ex }}=\right.$ $325 \mathrm{~nm}$ ) was used as an excitation source for PL, while Raman spectra were recorded under excitation at $632.8 \mathrm{~nm}$ line of a He-Ne laser. A charge-coupled device (CCD) detector (Tokyo, Japan) was used to collect the scattered light dispersed by a 600 lines $\cdot \mathrm{mm}^{-1}$ grating. The spectral resolution of the system used was $1.5 \mathrm{~cm}^{-1}$ for micro-Raman measurements and $0.1 \mathrm{~nm}$ for PL measurements.

A VG Microtech model MT500 spectrophotometer (Fison Instruments, Glasgow, UK) with a non-monochromatic $\mathrm{MgK}_{\alpha} 1.2 \mathrm{X}$-Ray source operating at $300 \mathrm{~W}$ was used. The X-ray photoelectron spectroscopy (XPS) analysis chamber pressure was maintained below $10^{-8}$ torr during data acquisition. Calibration of the energy scale was performed with an $\mathrm{Ag} \mathrm{3d^{5/2 }}$ (368.3 eV) standard. The peaks were fitted using a Gaussian-Lorentzian mixed function after a Shirley background subtraction. C1s sp ${ }^{2}$ at $284.5 \mathrm{eV}$ was used as binding energy (BE) reference.

\subsection{Adsorption Experiments}

Dysprosium adsorption by both activated carbons (AC-CA and AC-PA) was carried out via batch experiments. Stock solution of dysprosium $\left(1000 \mathrm{mg} \cdot \mathrm{L}^{-1}\right)$ were prepared by dissolving $\mathrm{Dy}\left(\mathrm{NO}_{3}\right)_{3} \cdot \mathrm{xH}_{2} \mathrm{O}$ (Merck KGaA, Damstadt, Germany) in MilliQ water. Then, stock solution was diluted to obtain the different concentrations. The temperature was controlled using a Selecta Termotronic thermostat bath equipped with multiple Lab Companion MS-52M stirrers. Aliquots $(1 \mathrm{~mL})$ of the solution were extracted every $15 \mathrm{~min}$ and filtered through a syringe filter with a $0.22 \mu \mathrm{m}$ pore and $13 \mathrm{~mm}$ diameter. The $\mathrm{pH}$ of the solutions was adjusted with $\mathrm{HCl}(0.1 \mathrm{M})$ until the desirable value was achieved. Dysprosium content in the solution was analyzed by Inductively Coupled Plasma-Optical Emission Spectrometry (ICP-OES) using an Agilent ICP-OES (Agilent Technologies, Sana Clara, CA, USA), model 5100 VDV (Vertical Dual View).

The dysprosium adsorbed percentage and the adsorption capacity at each time $\mathrm{t}\left(\mathrm{q}_{\mathrm{t}}\left(\mathrm{mg} \cdot \mathrm{g}^{-1}\right)\right)$ were calculated by the following equations:

$$
\begin{gathered}
\text { Adsorbed Dy }=\frac{\left(\mathrm{c}_{0}-\mathrm{c}_{\mathrm{e}}\right)}{\mathrm{c}_{0}} \cdot 100 \\
\mathrm{q}_{\mathrm{t}}=\frac{\left(\mathrm{C}_{0}-\mathrm{C}_{\mathrm{e}}\right) \cdot \mathrm{V}}{\mathrm{m}}
\end{gathered}
$$

The equilibrium adsorption isotherm data were plotted using the linear forms of Langmuir (Equation (3)), Freundlich (Equation (4)), and Temkin (Equation (5)) models [16]:

Langmuir:

$$
\frac{\mathrm{C}_{\mathrm{e}}}{\mathrm{q}_{\mathrm{e}}}=\frac{1}{\mathrm{q}_{\mathrm{m}} \cdot \mathrm{b}}+\frac{1}{\mathrm{q}_{\mathrm{m}}} \cdot \mathrm{c}_{\mathrm{e}}
$$

Freundlich:

$$
\ln \mathrm{q}_{\mathrm{e}}=\ln \mathrm{K}_{\mathrm{F}}+\frac{1}{\mathrm{n}} \cdot \ln \mathrm{C}_{\mathrm{e}}
$$

Temkin:

$$
\mathrm{q}_{\mathrm{e}}=\mathrm{B} \cdot \ln \mathrm{A}_{\mathrm{T}}+\mathrm{B} \cdot \ln \mathrm{c}_{\mathrm{e}}
$$

Kinetics experiments were analyzed using the pseudo-first-order (Equation (6)) and pseudo-second-order (Equation (7)) models, and were carried out at different temperatures:

Pseudo-first order [17]:

$$
\ln \left(q_{e}-q_{t}\right)=\ln q_{e}-K_{1} \cdot t
$$

Pseudo-second order [18]:

$$
\frac{t}{q_{t}}=\frac{1}{K_{2} \cdot q_{e}^{2}}+\frac{1}{q_{e}} \cdot t
$$


Activation energy $\left(E_{a}\right)$ can be calculated from the Arrhenius equation (Equation (8)) expressed as:

$$
\mathrm{k}_{2}=\mathrm{A} \cdot \mathrm{e}^{\left(\frac{-\mathrm{E}_{\mathrm{a}}}{\mathrm{R} \cdot \mathrm{T}}\right)}
$$

Enthalpy change $\left(\Delta \mathrm{H}^{0}\right)$ and entropy change $\left(\Delta \mathrm{S}^{0}\right)$ were calculated from the slope and intercept of a plot of $\log \left(\mathrm{q}_{\mathrm{e}} / \mathrm{c}_{\mathrm{e}}\right)$ versus 1/T [19] using the equations (Equation (9)) and (Equation (10)):

$$
\begin{gathered}
\log \frac{\mathrm{q}_{\mathrm{e}}}{\mathrm{C}_{\mathrm{e}}}=\frac{\Delta \mathrm{S}^{0}}{2.303 \mathrm{R}}+\frac{\Delta \mathrm{H}^{0}}{2.303 \mathrm{RT}} \\
\Delta \mathrm{G}^{0}=\Delta \mathrm{H}^{0}-\mathrm{T} \Delta \mathrm{S}^{0}
\end{gathered}
$$

\section{Results and Discussion}

\subsection{Characterization of the Activated Carbons}

\subsubsection{Textural Properties}

The pore volume, pore size, and the total specific surface area on AC-CA and AC-PA activated carbons were determined by the BET equation. AC-CA with a basically microporous structure were obtained, as can be seen in Table 1 , with the total pore volume $\left(V_{p}\right)$ very similar to the volume of micropores $\left(\mathrm{W}_{0}\right)$ a pore diameter $\left(\mathrm{D}_{\mathrm{p}}\right)$ of $<3.29 \mathrm{~nm}$ (micropores). The BET surface area is $2330 \mathrm{~m}^{2} \cdot \mathrm{g}^{-1}$. In the AC-PA, the volume of micropores is much lower than the total pore volume, which indicate that it is a mesoporous material, with pores of $4.8 \mathrm{~mm}$. The non-microporous surface is much larger that

\begin{tabular}{|c|c|c|c|c|c|c|}
\hline Sample & $\mathrm{V}_{\mathrm{T}}\left(\mathrm{cm}^{3} \cdot \mathrm{g}^{-1}\right)$ & $V_{\mu p}\left(\mathrm{~cm}^{3} \cdot \mathrm{g}^{-1}\right)$ & $D_{p}(n m)$ & $S_{\mu S}\left(m^{2} \cdot g^{-1}\right)$ & $\mathrm{NS}_{\mu \mathrm{s}}\left(\mathrm{m}^{2} \cdot \mathrm{g}^{-1}\right)$ & $\mathrm{S}_{\mathrm{BET}}\left(\mathrm{m}^{2} \cdot \mathrm{g}^{-1}\right)$ \\
\hline AC-QA & 1.17 & 1.07 & 3.29 & 2265.0 & 65.6 & 2330.6 \\
\hline AC-PA & 1.03 & 0.03 & 5.68 & 244.8 & 736.8 & 981.6 \\
\hline
\end{tabular}
the microporous surface, in accordance with the previous data. The specific BET surface is $981 \mathrm{~m}^{2} \cdot \mathrm{g}^{-1}$.

Table 1. Textural characterization of the activated carbons.

Texturally, both activated carbons are very different. Consequently, they should exhibit different behavior in the Dy adsorption process.

The $\mathrm{N}_{2}$ adsorption isotherm of AC-CA (Figure 1a) is of type I, according to the International Union of Pure and Applied Chemistry (IUPAC) classification [20]. This isotherm is characteristic of microporous solids. Figure $1 \mathrm{~b}$ shows the pore size distribution (Barrett-Joyner-Halenda $(\mathrm{BJH})$ desorption). The average pore diameter is $3.29 \mathrm{~nm}$. In the case of AC-PA, the adsorption isotherm (Figure 1c) is of type IV, with characteristics of solid that present aggregates of particles in the form of slit-shaped. The pore size distribution (Figure 1d) shows an average pore diameter of $5.68 \mathrm{~nm}$. 

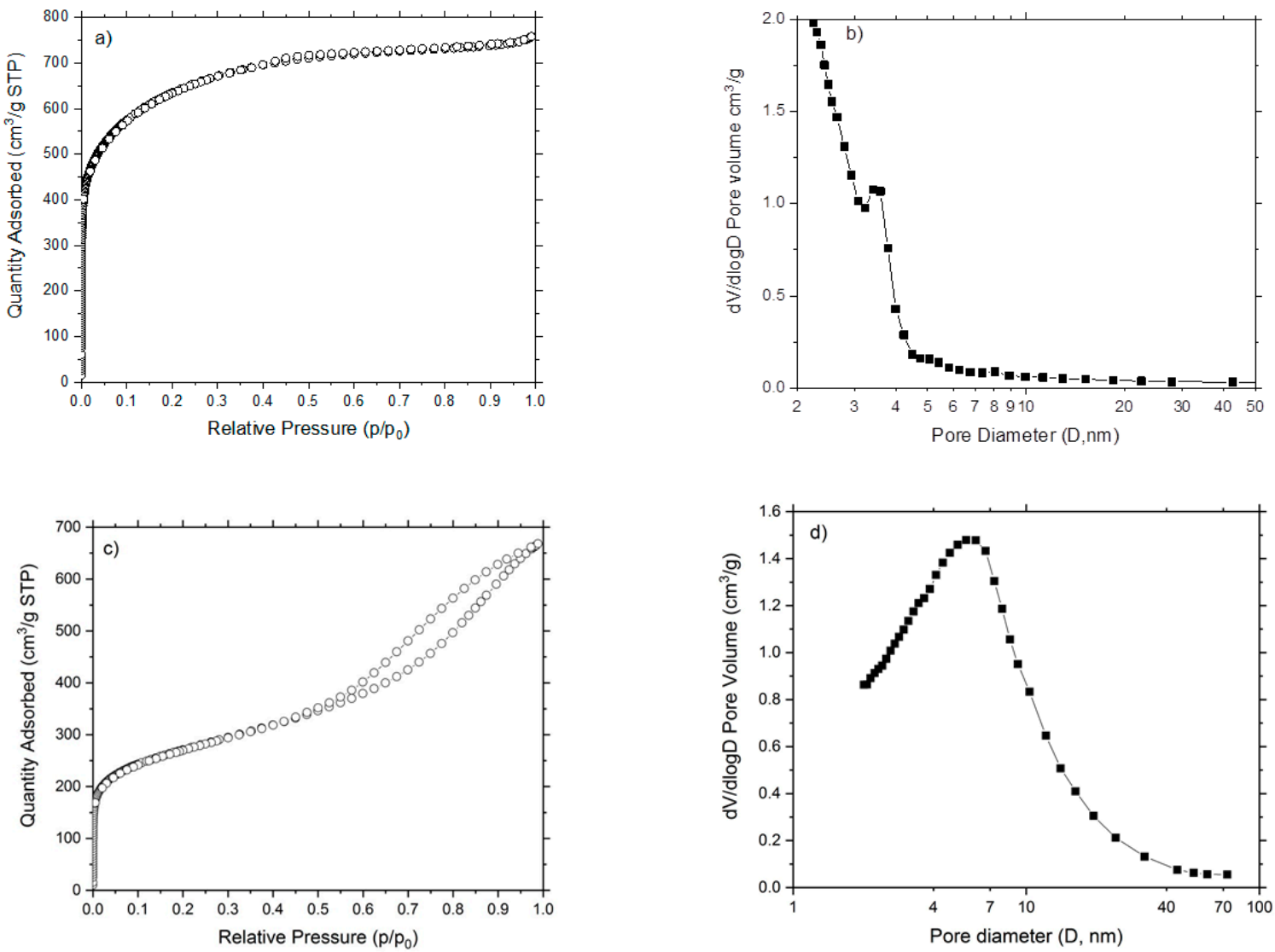

Figure 1. Adsorption isotherms and pore size distributions of $(\mathbf{a}, \mathbf{b})$ AC-CA and (c,d) AC-PA.

\subsubsection{Scanning Electron Microscopy (SEM)}

The surface characteristics of the activated carbons were analyzed using the SEM technique. Different morphologies can be clearly observed. The chemically activated carbons (Figure 2a) show homogeneous surface morphology with a large number of pores caused by the chemical interaction between $\mathrm{KOH}$ and the precursor surface. On the other hand, AC-PA (Figure 2b) exhibit a surface less porous than in the case described above, with a pitted and cracked surface typical of the physically activated carbons [21].

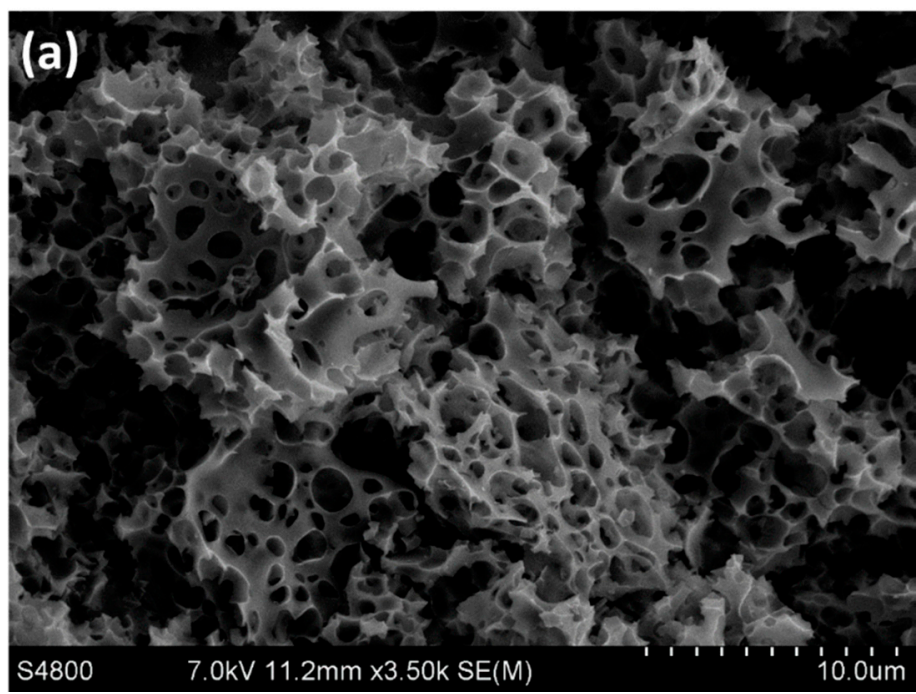

Figure 2. Cont. 


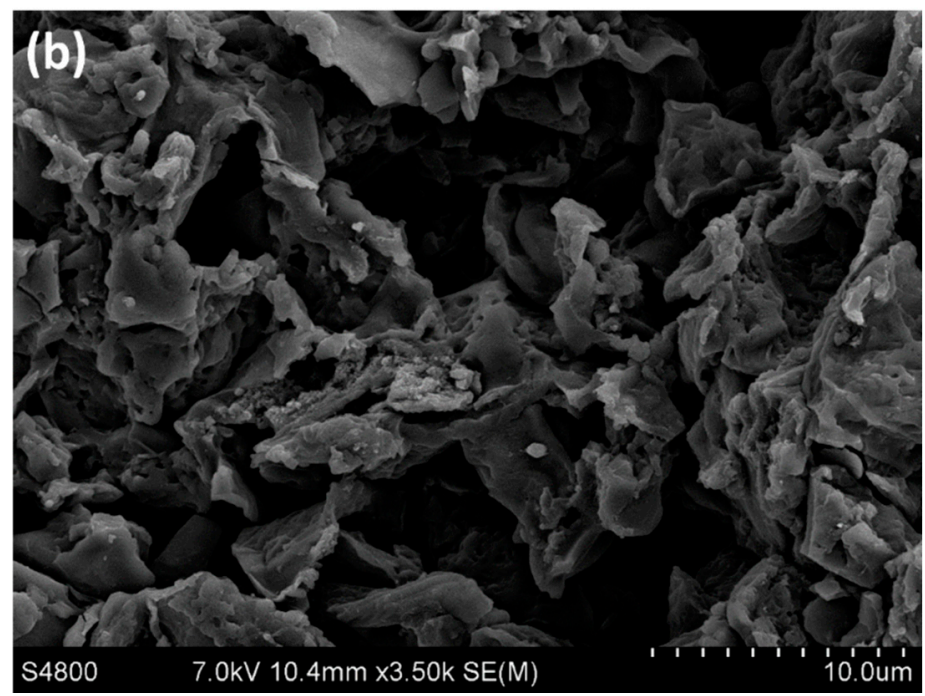

Figure 2. SEM micrographs of (a) AC-CA and (b) AC-PA samples.

\subsubsection{Raman Spectroscopy}

Characterization of both active carbons was carried out by Raman spectroscopy. Raman spectroscopy is a useful technique for carbon materials, because the spectral shape drastically changes not only due to the kind of abundant allotropic forms of carbon, but also to the fine structural changes of the individual allotrope [22]. In this sense, polycrystalline graphites exhibit two sharp peaks: G-band (at around $1580 \mathrm{~cm}^{-1}$ ) and D-band (at around $1355 \mathrm{~cm}^{-1}$ ). These bands are generally attributed to $\mathrm{E}_{2 \mathrm{~g}}$ and $\mathrm{A}_{1 \mathrm{~g}}$ in-plane vibration modes, respectively, and the graphitization degree of a carbon material is generally characterized by the $\mathrm{I}_{\mathrm{G}} / \mathrm{I}_{\mathrm{D}}$ value in the Raman spectra. Both vibration modes are represented schematically in Figure 3. In part A of the scheme, the breathing mode $A_{1 g}$ (D-band) is shown, while part $B$ illustrates the vibration mode $E_{2 g}$ ( $G$ band) $[23,24]$. On the other hand, in amorphous carbon, a broad band around $1550 \mathrm{~cm}^{-1}$ overlapped with a broader band around $1400 \mathrm{~cm}^{-1}$ is observed [22,25].

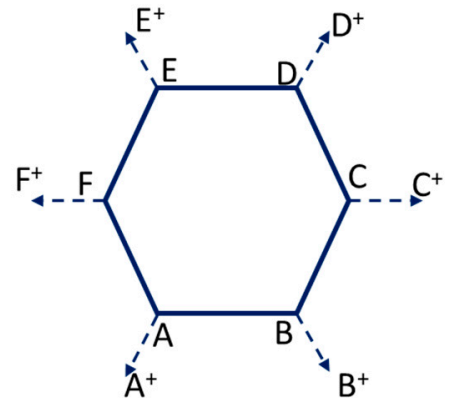

a

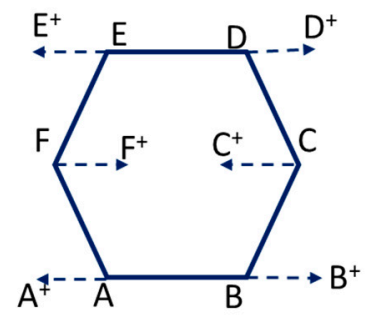

b

Figure 3. Scheme of the vibration modes: (a) Breathing mode $A_{1 g}$ (D-peak) and (b) Vibration mode $E_{2 g}$ (G-peak).

Comparative normalized spectra of AC-CA and AC-PA activated carbons are shown in Figure 4. Both samples exhibit two Raman bands peaked at $1595 \mathrm{~cm}^{-1}$ and $1334 \mathrm{~cm}^{-1}$. A broadening of the Raman bands can be appreciated in the AC-CA sample in comparison to the AC-PA sample. In addition, the Raman bands centered at $1334 \mathrm{~cm}^{-1}$ exhibit the higher intensity in both cases. This effect is more noticeable in the AC-PA activated carbon spectrum. 


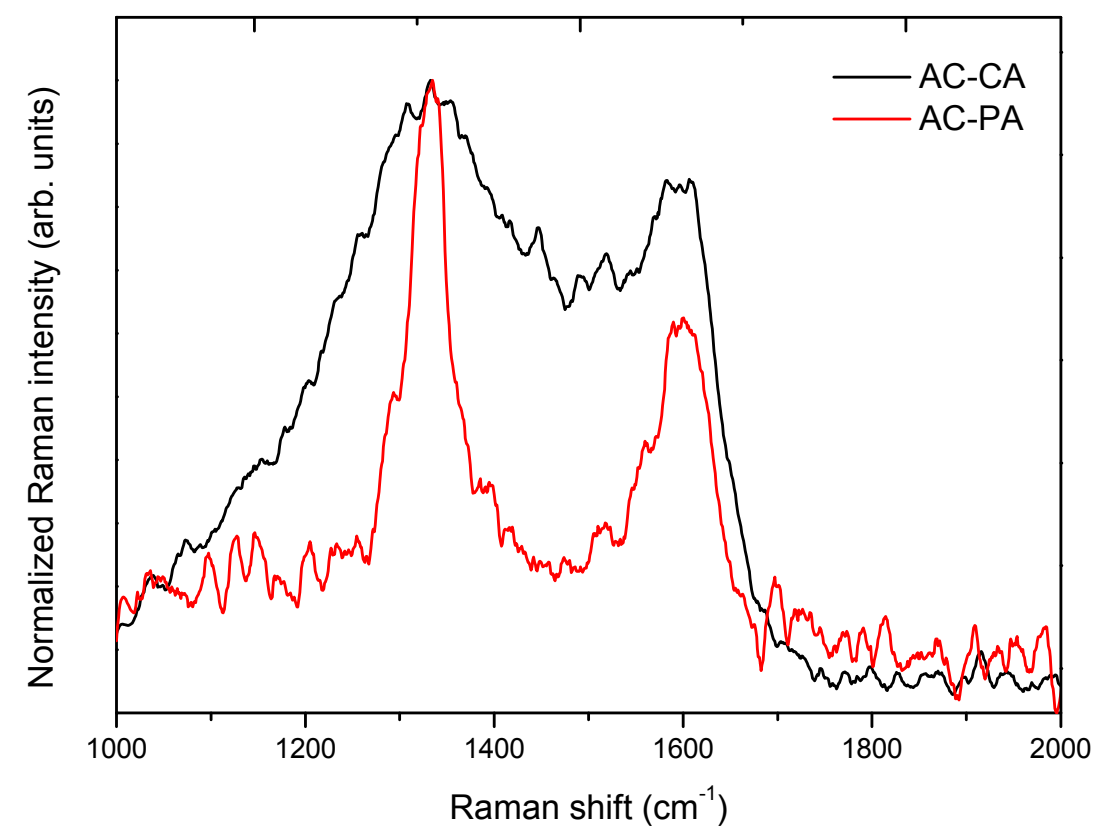

Figure 4. Normalized Raman spectra of both activated carbons.

In the present case, the $\mathrm{I}_{\mathrm{G}} / \mathrm{I}_{\mathrm{D}}(\mathrm{AC}-\mathrm{PA})>\mathrm{I}_{\mathrm{G}} / \mathrm{I}_{\mathrm{D}}(\mathrm{AC}-\mathrm{CA})$, which indicate the highest graphitization degree of the AC-PA activated carbon sample. Previous investigations carried out with carbon nanomaterials reported that the adsorption capacity is related with the graphitization degree [24].

\subsection{Adsorption Experiments}

We have studied the influence of three different parameters on the adsorption capacity of both types of activated carbons: Solution $\mathrm{pH}$, Dy concentration, and activated carbon amount.

\subsubsection{Influence of the Solution $\mathrm{pH}$}

In order to analyze the influence of the solution $\mathrm{pH}$ on the adsorption process, experiments were carried out at three different $\mathrm{pH}$ values ( 3 to 5 ). For this purpose, $30 \mathrm{mg}$ of the activated carbons were added to $200 \mathrm{~mL}$ solution containing $5 \mathrm{mg} \cdot \mathrm{L}^{-1}$ of Dy ions. The adsorbed dysprosium amounts versus the contact time at different $\mathrm{pH}$ values for both types of $\mathrm{AC}$ are plotted in Figure 5.

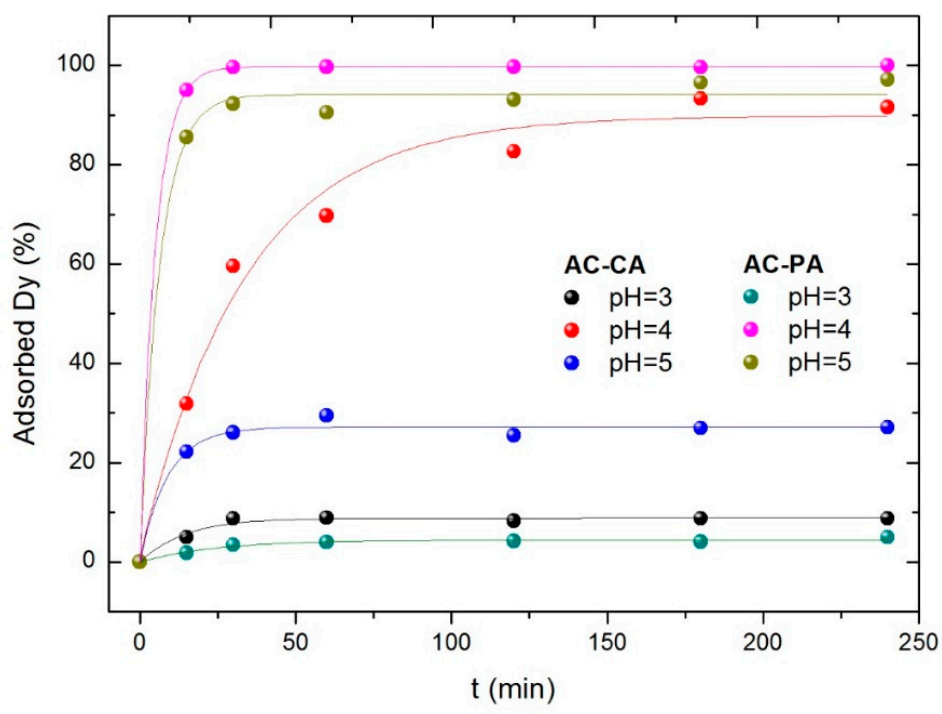

Figure 5. Effect of the solution $\mathrm{pH}$ for AC-CA and AC-PA. 
In both cases (AC-CA and AC-PA), the adsorption capacity increases when the $\mathrm{pH}$ increases from 3 to 4 and then decreases. As previously reported [26], dysprosium may be present in the solution either as an isolated cation $\left(\mathrm{Dy}^{3+}\right)$ or as hydroxide cation $\left(\mathrm{Dy}(\mathrm{OH})^{2+}\right)$. Consequently, the behavior in aqueous solution is a complex phenomenon. According to Qaader et al. [26], at a pH between 1 and 4, the predominant species is $\mathrm{Dy}^{3+}$, while at higher $\mathrm{pH}$ values $\mathrm{Dy}^{3+}$ ions start to become hydrolyzed, leading to the formation of other species such as $\mathrm{Dy}(\mathrm{OH})^{2+}$.

These species are weakly adsorbed as compared to $\mathrm{Dy}^{3+}$ ions. Therefore, the adsorption of dysprosium starts to decrease above $\mathrm{pH} 5$, and the highest adsorption was found at value of $\mathrm{pH}$ of 4, obtaining a maximum adsorption percentage of $94 \%$ for AC-CA and practically $100 \%$ for AC-PA. The adsorption capacity of AC-PA was higher than AC-CA for all $\mathrm{pH}$ values investigated.

\subsubsection{Influence of the Dysprosium Concentration}

The influence of dysprosium concentration has been studied with three solutions with Dy concentrations of $2.5,5$, and $10 \mathrm{mg} / \mathrm{L}$, and a fixed amount $(30 \mathrm{mg})$ of activated carbon. All the experiments were carried out at room temperature. The results are shown in Figure 6.

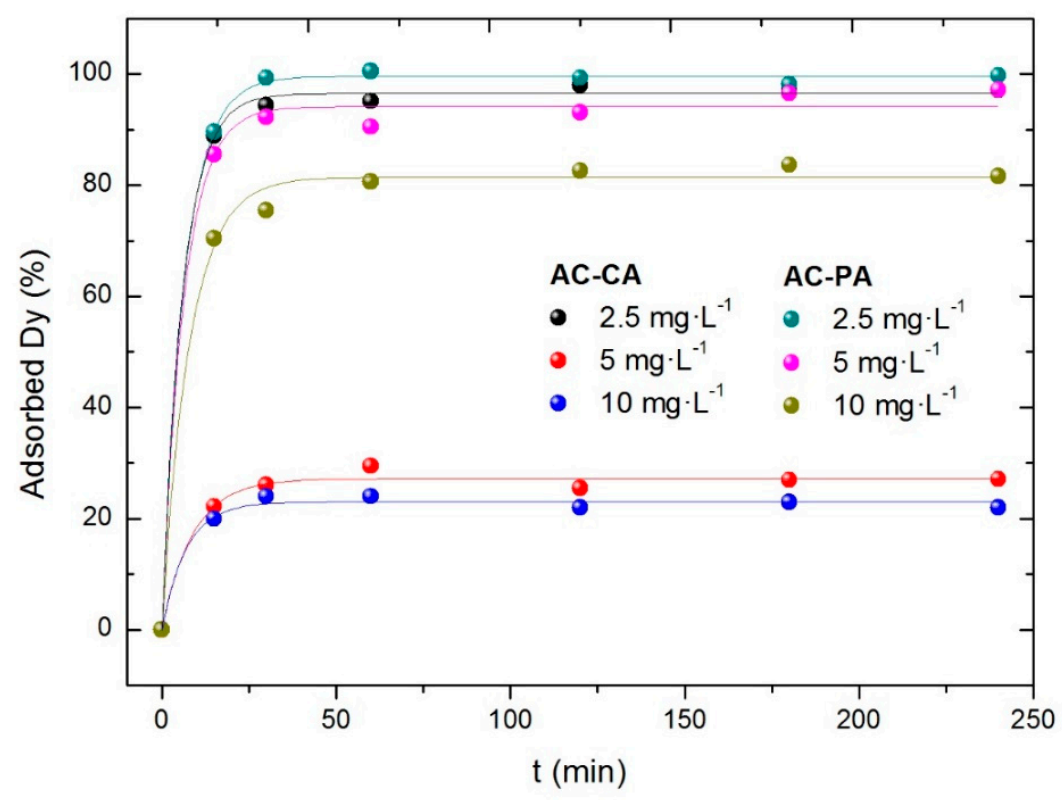

Figure 6. Effect of the dysprosium concentration in the adsorption percentage.

In both cases (AC-CA and AC-PA), the adsorbed Dy percentage decreases with increasing RE concentration. In the case of AC-PA, the adsorption percentages are quite high, ranging from $99 \%$ for the lowest Dy concentration to $80 \%$ for the largest. However, the AC-CA samples show lower adsorption percentages. In fact, a significant adsorption, $96 \%$, is obtained (similar to that of AC-PA) only for the solution with the lowest Dy concentration. For the solutions with 5 and $10 \mathrm{mg} \cdot \mathrm{L}^{-1}$ of Dy, much lower adsorption capacities are observed, between 20 and 30\%.

\subsubsection{Influence of the Activated Carbon Amount}

Finally, the influence of the adsorbent amount was studied. Solutions of Dy with $5 \mathrm{mg} \cdot \mathrm{L}^{-1}$ of concentration were put in contact with different amounts of both ACs $(5,15,30$, and $60 \mathrm{mg})$. The results are plotted in Figure 7. 


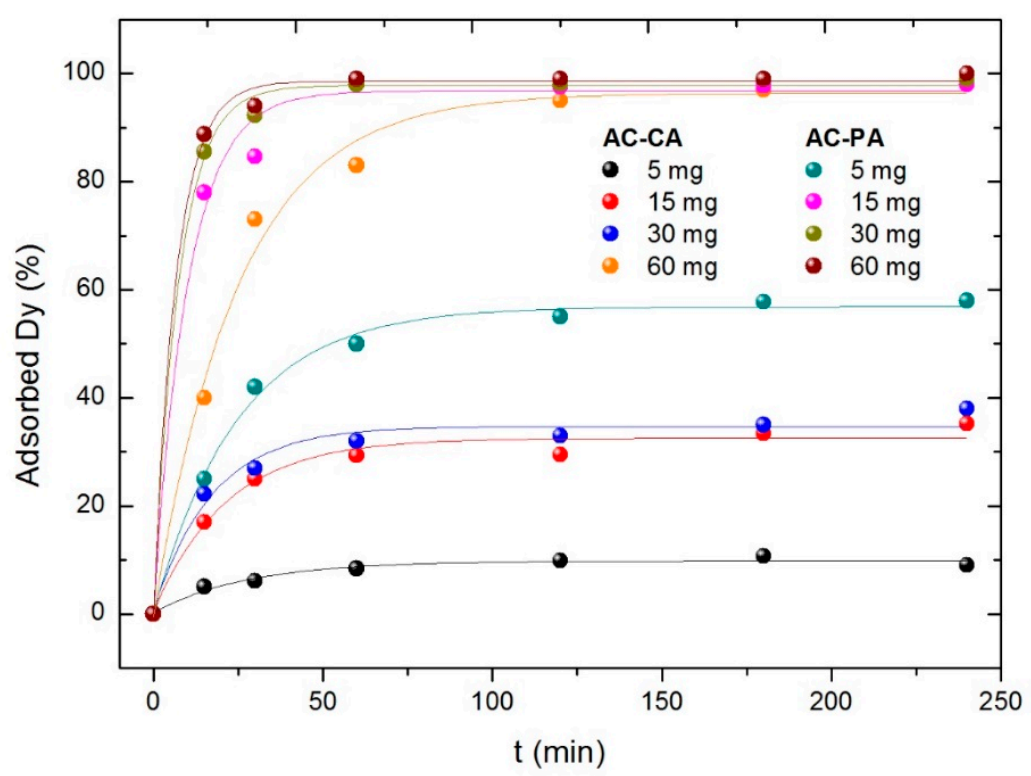

Figure 7. Variation of the adsorption percentage with the adsorbent amount.

As for the other parameters, the best results are obtained for the AC-PA. As expected, the larger the amount of adsorbent, the larger the adsorption percentage. However, the behavior of the two kinds of samples is significantly different. In the case of the AC-PA, the adsorption percentage increases drastically (from $57 \%$ to $99 \%$ ) when the AC amount increases from $5 \mathrm{mg}$ to $15 \mathrm{mg}$. Then, it remains practically constant with the amount of adsorbent. However, in the case of the AC-CA, the adsorption depends strongly on the adsorbent amount, going from $10 \%$ (5 mg of the AC) to $96 \%$ (60 $\mathrm{mg}$ of the $\mathrm{AC})$. Only the largest adsorbent amount the adsorption percentage is comparable to those of AC-PA, and even in this case, the time required to reach a similar adsorption percentage is much longer. Comparable values are reached only for the largest adsorbent amount $(60 \mathrm{mg})$ and times around $120 \mathrm{~min}$.

\subsubsection{Equilibrium Isotherms}

As observed from the previously shown adsorption results (Figures 4-6), the equilibrium adsorption percentage is reached after a period of time ranging from approximately 50 to $120 \mathrm{~min}$ depending on the experiment conditions. For the sake of the kinetic study, we will adopt those obtained at $120 \mathrm{~min}$ as equilibrium values since, at this time, the equilibrium has been achieved in all the experimental conditions.

Equilibrium isotherms were measured modifying the adsorbent amount and using Equations (3)-(5). In Table 2, the calculated parameters and the corresponding correlation coefficients are shown. For both ACs, the best correlation is obtained with the Langmuir model. According to this model, the maximum adsorption capacity values $\left(\mathrm{q}_{\mathrm{m}}\right)$ calculated were $28.11 \mathrm{mg} \cdot \mathrm{g}^{-1}$ and $29.05 \mathrm{mg} \cdot \mathrm{g}^{-1}$ for AC-CA and AC-PA, respectively. These results are similar to those obtained experimentally (31.26 $\mathrm{mg} \cdot \mathrm{g}^{-1}$ and $\left.33.52 \mathrm{mg} \cdot \mathrm{g}^{-1}\right)$. As expected, according to the previously discussed results, the AC-PA showed the greatest adsorption capacity. The values calculated for Langmuir nondimensional factors (RL) are 0.02 and 0.03 for AC-CA and AC-PA respectively, which indicates that the dysprosium adsorption is a favorable process. 
Table 2. Calculated isotherm parameters for the Langmuir, Freundlich, and Temkin linear models.

\begin{tabular}{|c|c|c|c|c|c|c|c|c|c|c|}
\hline \multirow{2}{*}{ Sample } & \multicolumn{4}{|c|}{ Langmuir } & \multicolumn{3}{|c|}{ Freundlich } & \multicolumn{3}{|c|}{ Temkin } \\
\hline & $\mathrm{q}_{\mathrm{m}}\left(\mathrm{mg} \cdot \mathrm{g}^{-1}\right)$ & $b\left(L \cdot m^{-1}\right)$ & $\mathbf{R}_{\mathbf{L}}$ & $\mathbf{R}^{2}$ & $K_{F}\left(L \cdot g^{-1}\right)$ & $1 / n$ & $\mathbf{R}^{2}$ & $\mathbf{A}_{\mathrm{T}}$ & $\mathbf{b}_{\mathrm{T}}$ & $\mathbf{R}^{2}$ \\
\hline AC-CA & 28.11 & 6.42 & 0.02 & 0.996 & 24.82 & 0.08 & 0.713 & 0.23 & 0.16 & 0.582 \\
\hline AC-PA & 29.05 & 10.5 & 0.03 & 0.998 & 81.44 & 0.17 & 0.722 & 0.79 & 0.10 & 0.800 \\
\hline
\end{tabular}

\subsubsection{Effect of the Temperature, Kinetic and Thermodynamic Study}

Experiments at different three temperatures $(303,318$, and $333 \mathrm{~K})$ were carried out to evaluate the influence of temperature on adsorption process. For this experiment, $30 \mathrm{mg}$ of the AC were put in contact with a Dy dissolution with a concentration of $5 \mathrm{mg} \cdot \mathrm{L}^{-1}$. As can be seen in Figure 8 , the behavior of both types of samples is considerably different. In the AC-PA samples, temperature does not seem to play a significant role (within the temperature interval under consideration). For all temperatures investigated, the equilibrium value is reached after a relatively short time (around $25 \mathrm{~min}$ ). In the case of the AC-CA sample, at the lowest temperature, a very low adsorption degree is reached $(27 \%)$. At $318 \mathrm{~K}$, the adsorption percentage is closer to that obtained for AC-PA samples. At $333 \mathrm{~K}$, similar values are obtained for both types of activated carbons.

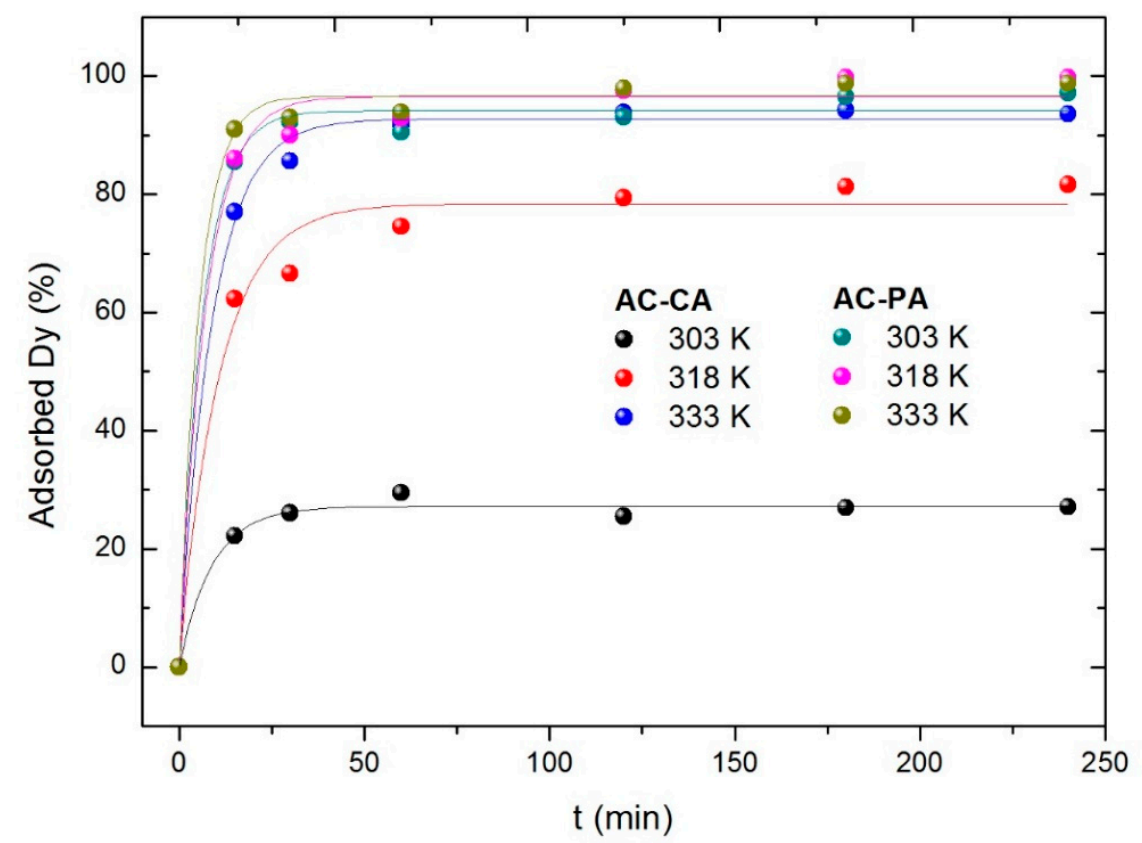

Figure 8. Dysprosium (Dy) adsorption percentage with the temperature variation.

Adsorption kinetics studies were carried out using Equations (6) and (7). The calculated parameters from the corresponding fits are included in Table 3. For both type of samples, the best fitted results were found for a pseudo-second-order model. With respect to the kinetic reaction constants, $\mathrm{k}_{2}$ increases as the temperature increases, which indicates that the temperature favors the adsorption process. In fact, if we consider the $k_{2}$ values obtained for AC-CA samples, the influence of temperature seems to be larger than for the AC-PA samples, in agreement with the results described from Figure 8. 
Table 3. Calculated kinetics parameters at different temperatures.

\begin{tabular}{cccccccc}
\hline \multirow{2}{*}{ Sample } & \multirow{2}{*}{$\mathbf{T}(\mathbf{K})$} & \multicolumn{3}{c}{ Pseudo-First-Order } & \multicolumn{3}{c}{ Pseudo-Second-Order } \\
\cline { 2 - 8 } & & $\mathbf{k}_{\mathbf{1}}$ & $\mathbf{q}$ & $\mathbf{R}^{\mathbf{2}}$ & $\mathbf{k}_{\mathbf{2}} \mathbf{( \cdot \mathbf { 1 0 }} \mathbf{3}$ & $\mathbf{q}$ & $\mathbf{R}^{\mathbf{2}}$ \\
\hline \multirow{3}{*}{ AC-CA } & 303 & 0.016 & 17.693 & 0.784 & 0.795 & 32.362 & 0.997 \\
\cline { 2 - 8 } & 318 & 0.017 & 19.470 & 0.830 & 1.012 & 32.467 & 0.995 \\
\cline { 2 - 8 } & 333 & 0.057 & 19.931 & 0.933 & 10172 & 33.670 & 0.999 \\
\hline \multirow{3}{*}{ AC-PA } & 303 & 0.020 & 8.194 & 0.740 & 0.932 & 28.490 & 0.999 \\
\cline { 2 - 8 } & 318 & 0.023 & 8.366 & 0.965 & 1.132 & 30.120 & 0.999 \\
\cline { 2 - 8 } & 333 & 0.047 & 21.270 & 0.785 & 1.232 & 32.362 & 0.999 \\
\hline
\end{tabular}

As explained in Section 2.2, activation energy was estimated the linear form Arrhenius equation plot $\ln k_{2, o b s}$ versus $1 / T$. The value of the activation energy will give us information on the character of the adsorption process. For physical adsorption process, the reactions are reversible, the equilibrium are rapidly achieved, and the activation energies are correspondingly low in the range from 5 to 40 $\mathrm{kJ} \cdot \mathrm{mol}^{-1}$. On the contrary, chemical adsorption involves stronger forces and hence requires higher activation energies ( 40 to $800 \mathrm{~kJ} \cdot \mathrm{mol}^{-1}$ ) [27]. In our case, the calculated activation energies were 10.90 $\mathrm{kJ} \cdot \mathrm{mol}^{-1}$ and $7.83 \mathrm{~kJ} \cdot \mathrm{mol}^{-1}$ for AC-CA and AC-PA, respectively, suggesting a physisorption process.

Table 4 summarizes the thermodynamic parameters calculated from Equations (8)-(10). The negative values obtained for the enthalpy change indicate that the dysprosium adsorption is an exothermic process in all the samples studied. Moreover, the adsorption process is spontaneous and favorable at the different temperatures studied for both ACs, as indicated by the free energy change [28]. Finally, the value calculated for the entropy change was positive in both cases, indicating that the entropy of the system increased during the adsorption, i.e., as mentioned previously, it is a spontaneous process. These results described are indicative of the affinity of the ACs toward Dy ions [27]. Besides, the positive values suggest an increase in adsorbate concentration in the solid-liquid interface (an increase in adsorbate concentration onto the solid phase) [29].

Table 4. Calculated thermodynamic kinetics parameters for both activated carbons (ACs).

\begin{tabular}{|c|c|c|c|c|}
\hline Sample & $\mathrm{T}(\mathrm{K})$ & $-\Delta \mathrm{H}^{0}\left(\mathrm{~kJ} \cdot \mathrm{mol}^{-1}\right)$ & $\Delta S^{0}\left(\mathrm{~J} \cdot \mathrm{mol}^{-1} \cdot \mathrm{K}^{-1}\right)$ & $-\Delta \mathrm{G}^{0}\left(\mathrm{~kJ} \cdot \mathrm{mol}^{-1}\right)$ \\
\hline \multirow{3}{*}{ AC-CA } & 303 & \multirow{3}{*}{79.18} & \multirow{3}{*}{327.64} & 178.45 \\
\hline & 318 & & & 183.37 \\
\hline & 333 & & & 188.29 \\
\hline \multirow{3}{*}{ AC-PA } & 303 & \multirow{3}{*}{159.65} & \multirow{3}{*}{628.29} & 350.02 \\
\hline & 318 & & & 359.44 \\
\hline & 333 & & & 368.87 \\
\hline
\end{tabular}

\subsection{X-Ray Photoelectron Spectroscopy (XPS)}

The shape of high-resolution Dy 4d XPS spectra and its binding energy were carefully analyzed (Figure 9). The Dy spectra exhibit doublet components due to the electrostatic interactions of the $4 \mathrm{~d}$ hole and $4 \mathrm{f}$ electrons with spin-orbit splitting of $4 \mathrm{~d}^{5 / 2}$ and $4 \mathrm{~d}^{3 / 2}$ states. In the case of $\mathrm{Dy}\left(\mathrm{NO}_{3}\right)_{3}$, the characteristic doublet peak appears at $154.2 \mathrm{eV}$ for $4 \mathrm{~d}^{5 / 2}$ and $157.4 \mathrm{eV}$ for $4 \mathrm{~d}^{3 / 2}$, which is according to the standard oxidation state of +3 [30]. The binding energy of Dy $4 d^{5 / 2}$ for samples AC-PA:Dy and AC-CA:Dy are $155.0 \mathrm{eV}$ and $153.9 \mathrm{eV}$, respectively. These results confirm that the Dy remains in the state of $\mathrm{Dy}^{3+}$ after treatment, but in the case of the sample AC-CA:Dy, its BE value is very close to the obtained for $\mathrm{Dy}\left(\mathrm{NO}_{3}\right)_{3}$ standard, which means that there is no significant difference in the chemistry of Dy in both samples. However, in the case of AC-PA:Dy, there is a significant shift to higher binding 
energies. This could suggest a higher interaction between Dy and $C$ after this treatment. The obtained results can be indicative of a chemisorption process in the case of AC-PA activated carbon, despite the results obtained from thermodynamic studies. Nevertheless, in the case of the AC-CA, the adsorption could be a physisorption process.
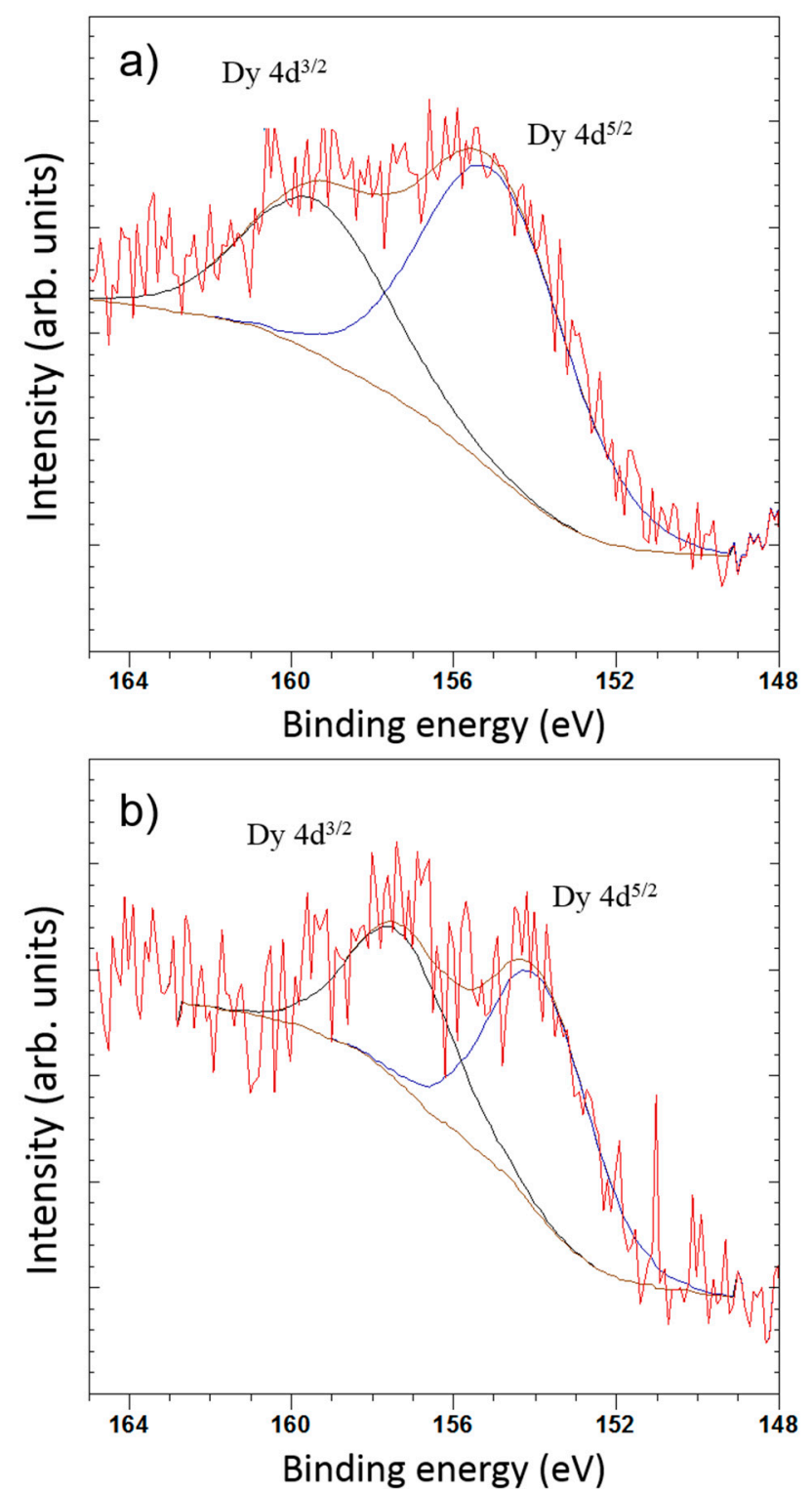

Figure 9. X-ray photoelectron spectroscopy (XPS) deconvolution spectra of Dy $4 \mathrm{~d}$ peak of (a) AC-PA:Dy and (b) AC-CA:Dy.

\subsection{Photoluminescence Spectroscopy (PL)}

Like most RE, dysprosium cations have a strong visible luminescent emission related to different intra-ionic transitions [31]. Luminescence spectra of $\mathrm{Dy}^{3+}$ active ions are composed of three characteristic bands centered at 480,575, and $664 \mathrm{~nm}$. These emissions can be attributed to ${ }^{4} \mathrm{~F}_{9 / 2}-{ }^{6} \mathrm{H}_{15 / 2},{ }^{4} \mathrm{~F}_{9 / 2}-{ }^{6} \mathrm{H}_{13 / 2}$, and ${ }^{4} \mathrm{~F}_{9 / 2}-{ }^{6} \mathrm{H}_{11 / 2}$ transitions, respectively [32]. Among them, the two first are the dominant components in the spectra [33]. The emission intensity of $\mathrm{Dy}^{3+}$ ions may strongly depend on the host matrix, which may significantly influence the radiative and non-radiative properties (multiphonon relaxation as well as energy transfer) leading to different luminescent behavior [32]. 
Among the different emissions mentioned above, the ${ }^{4} \mathrm{~F}_{9 / 2}{ }^{-6} \mathrm{H}_{13 / 2}$ transition is the most sensitive and the ${ }^{4} \mathrm{~F}_{9 / 2}{ }^{6} \mathrm{H}_{15 / 2}$ transition is the less sensitive to the matrix [34].

The spectrum shown in Figure 10 corresponds to the AC-PA:Dy samples. The spectrum exhibits a dominant band peaked at $572 \mathrm{~nm}$ and a less intense band centered at around $478 \mathrm{~nm}$. These bands can be attributed to ${ }^{4} \mathrm{~F}_{9 / 2}-{ }^{6} \mathrm{H}_{13 / 2}$ and ${ }^{4} \mathrm{~F}_{9 / 2}-{ }^{6} \mathrm{H}_{15 / 2}$ transitions, respectively. No PL emission could be detected from the AC-CA:Dy samples. In the AC-PA:Dy samples, the dominant band is the ${ }^{4} \mathrm{~F}_{9 / 2}{ }^{6} \mathrm{H}_{13 / 2}$, sometimes referred as hypersensitive transition due to the high sensitivity to the host. Therefore, structural differences between both types of carbons could be behind the quenching of the luminescence observed in the AC-CA samples.

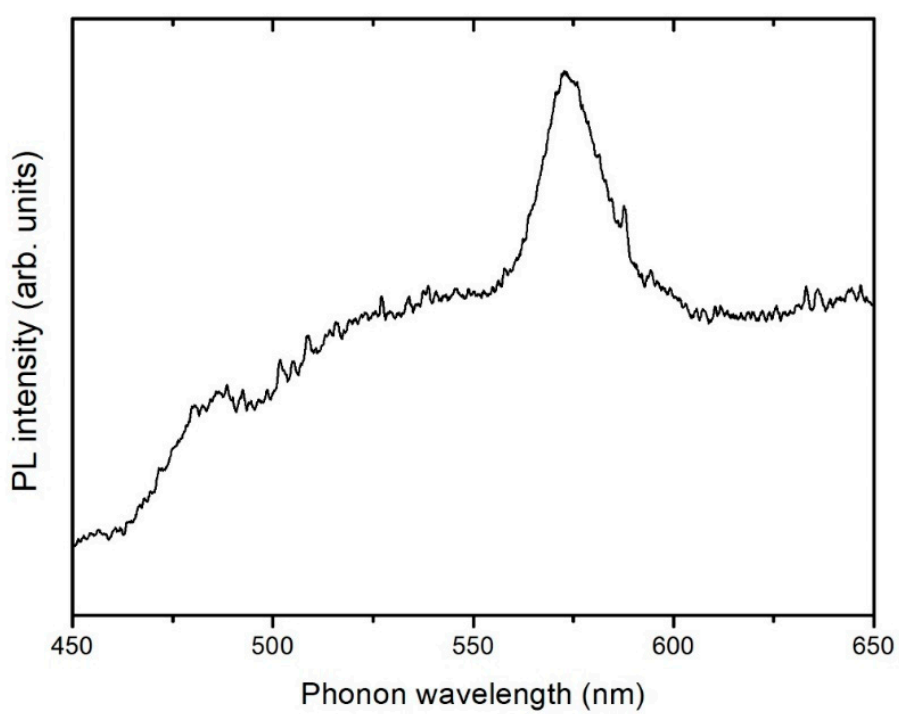

Figure 10. Photoluminescence (PL) spectrum of adsorbed dysprosium onto the AC-PA activated carbon.

\section{Conclusions}

Dysprosium adsorption experiments exhibit that the variation of the solution $\mathrm{pH}$ realizes a great influence in the process, obtaining the maximum adsorption at $\mathrm{pH} 4$. As an expected, a decreases of the solution Dy concentration increases the adsorption percentage. In addition, in the case of chemically activated carbon, the Dy absorbed amount gradually increases with the adsorbent dosage. This effect is not observed in the case of physically activated carbon, where with the exception of the lowest amount used, the adsorption percentage remains practically constant. Finally, the variation of the temperature slightly improves the adsorption process. Despite this, physically activated carbon exhibits a great adsorption capacity in all cases. The adsorption isotherms and the kinetic study were better fit with the Langmuir model and pseudo-second-order kinetics, respectively, for both investigated activated carbons. So, dysprosium adsorption onto both activated carbons is an exothermic, spontaneous, and favorable process, as indicated the obtained thermodynamic results. XPS measurements indicate that Dy ions remain in the +3 oxidation state after the adsorption process. Moreover, in the case of the AC-PA:Dy sample, a significant shift to higher binding energies was found indicating higher interaction between Dy ions and the AC. The PL spectrum of the Dy loaded AC-PA sample exhibit an emission intensity centered at $572 \mathrm{~nm}$ attributed to the $\mathrm{Dy}^{3+}$ ions. So, in the case of the AC-PA activated carbon, the Dy adsorption could be a chemisorption process.

Author Contributions: L.A. methodology, formal analysis tests, writing original draft preparation; M.E.E. formal analysis; F.J.A. conceptualization and methodology; I.L. formal analysis; A.U. formal analysis; P.F. formal analysis; writing-review; F.A.L. conceptualization and methodology, supervision, writing-review and editing.

Funding: This project has received funding from the European Union's Horizon 2020 research and innovation program under grant agreement No 776851 (carEService). 
Acknowledgments: This work has been carried out within the activities of the Card E-Service project.

Conflicts of Interest: The authors declare no conflict of interest.

\section{Nomenclature}

$\mathrm{C}_{0}\left(\mathrm{mg} \cdot \mathrm{L}^{-1}\right)$
$\mathrm{C}_{\mathrm{e}}\left(\mathrm{mg} \cdot \mathrm{L}^{-1}\right)$
$\mathrm{q}_{\mathrm{t}}\left(\mathrm{mg} \cdot \mathrm{g}^{-1}\right)$
$\mathrm{V}(\mathrm{L})$
$\mathrm{m}(\mathrm{g})$
$\mathrm{q}_{\mathrm{e}}\left(\mathrm{mg} \cdot \mathrm{g}^{-1}\right)$
$\mathrm{q}_{\mathrm{m}}\left(\mathrm{mg} \cdot \mathrm{g}^{-1}\right)$
$\mathrm{b}\left(\mathrm{L} \cdot \mathrm{mg}^{-1}\right)$
$\mathrm{K}_{\mathrm{F}}\left(\mathrm{L} \cdot \mathrm{g}^{-1}\right)$
$1 / \mathrm{n}\left(\mathrm{adimensional}^{-1}\right)$
$\mathrm{A}_{\mathrm{T}}\left(\mathrm{L} \cdot \mathrm{g}^{-1}\right)$
$\mathrm{T}(\mathrm{K})$
$\mathrm{B}\left(\mathrm{J} \cdot \mathrm{mol}^{-1}\right)$
$\mathrm{b}_{\mathrm{T}}$
$\mathrm{R}\left(\mathrm{kJ} \cdot \mathrm{K}^{-1} \cdot \mathrm{mol}^{-1}\right)$
$\mathrm{R}_{\mathrm{L}}(\mathrm{adimensional})$

$\mathrm{k}_{1}\left(\mathrm{~min}^{-1}\right)$
$\mathrm{k}_{2}\left(\mathrm{~g} \cdot \mathrm{mg}^{-1} \cdot \mathrm{min}^{-1}\right)$
A $\left(\mathrm{g} \cdot \mathrm{mg}^{-1} \cdot \mathrm{min}^{-1}\right)$
$\Delta \mathrm{H}^{0}\left(\mathrm{~kJ} \cdot \mathrm{mol}^{-1}\right)$
$\Delta \mathrm{S}^{0}\left(\mathrm{~J} \cdot \mathrm{mol}^{-1} \cdot \mathrm{K}^{-1}\right)$
$\Delta \mathrm{S}^{0}\left(\mathrm{~J} \cdot \mathrm{mol}^{-1} \cdot \mathrm{K}^{-1}\right)$
$\mathrm{V}_{\mathrm{T}}$
$\mathrm{V}_{\mu \mathrm{p}}$
$\mathrm{D}_{\mathrm{p}}$
$\mathrm{S}_{\mu \mathrm{s}}$
$\mathrm{NS}_{\mu \mathrm{s}}$

initial concentrations of the RE in solution equilibrium concentrations of the RE in solution adsorption capacity at each time $t$ volume of the solution mass of the activated carbon

$\mathrm{RE}$ adsorbed amount by mass of the $\mathrm{AC}$ at the equilibrium maximum adsorption capacity of the adsorbent per unit mass of adsorbate Langmuir constant Freundlich constant adsorption intensity Temkin isotherm equilibrium binding constant absolute temperature $\left((\mathrm{R} \cdot \mathrm{T}) / \mathrm{b} \_\mathrm{T}\right)$

Temkin isotherm constant universal gas constant Langmuir constant or equilibrium parameter. This parameter indicates if the isotherm is reversible $(R L=0)$, favorable $(0<R L<1)$, lineal $(R L=1)$ or unfavorable $(\mathrm{RL}>1)$ where $\mathrm{RL}=1 /(1+\mathrm{b} \cdot \mathrm{Co})$ pseudo-first-order adsorption constant pseudo-second-order adsorption constant temperature-independent factor standard enthalpy change standard entropy change standard Gibbs free energy total pore volume micropore volume average micropore diameter (BJH desorption) microporous surface non-microporous surface

\section{References}

1. Binnemans, K.; Jones, P.T.; Blanpain, B.; Van Gerven, T.; Yang, Y.; Walton, A.; Buchert, M. Recycling of rare earths: A critical review. J. Clean. Prod. 2013, 51, 1-22. [CrossRef]

2. Gradin, K.T.; Poulikidou, S.; Björklund, A.; Luttropp, C. Scrutinising the electric vehicle material backpack. J. Clean. Prod. 2018, 172, 1699-1710. [CrossRef]

3. Balaram, V. Rare earth elements: A review of applications, occurrence, exploration, analysis, recycling, and environmental impact. Geosci. Front. 2019, 10, 1285-1303. [CrossRef]

4. Alonso, E.; Sherman, A.M.; Wallington, T.J.; Everson, M.P.; Field, F.R.; Roth, R.; Kirchain, R.E. Evaluating Rare Earth Element Availability: A Case with Revolutionary Demand from Clean Technologies. Environ. Sci. Technol. 2012, 46, 3406-3414. [CrossRef] [PubMed]

5. González, A.G.; Pokrovsky, O.S.; Santana-Casiano, J.M.; González-Dávila, M. Bioadsorption of heavy metals. Prospect. Chall. Algal Biotechnol. 2017, 4, 233-255.

6. Fu, F.; Wang, Q. Removal of heavy metal ions from wastewaters: A review. J. Environ. Manag. 2011, 92, 407-418. [CrossRef] [PubMed]

7. De Gisi, S.; Lofrano, G.; Grassi, M.; Notarnicola, M. Characteristics and adsorption capacities of low-cost sorbents for wastewater treatment: A review. Sustain. Mater. Technol. 2016, 9, 10-40. [CrossRef]

8. Tahir, W.; Choudhry, S. Production of activated carbon from tea waste and its application in water treatment. J. Biol. Environ. Sci. 2017, 11, 37-44. 
9. Malhotra, M.; Suresh, S.; Garg, A. Tea waste derived activated carbon for the adsorption of sodium diclofenac from wastewater: Adsorbent characteristics, adsorption isotherms, kinetics, and thermodynamics. Environ. Sci. Pollut. Res. 2018, 25, 32210-32220. [CrossRef]

10. Suganya, S.; Kumar, P.S. Influence of ultrasonic waves on preparation of active carbon from coffee waste for the reclamation of effluents containing $\mathrm{Cr}(\mathrm{VI})$ ions. J. Ind. Eng. Chem. 2018, 60, 418-430.

11. Laksaci, H.; Khelifi, A.; Trari, M.; Addoun, A. Synthesis and characterization of microporous activated carbon from coffee grounds using potassium hydroxides. J. Clean. Prod. 2017, 147, 254-262. [CrossRef]

12. Alcaraz, L.; López Fernández, A.; García-Díaz, I.; López, F.A. Preparation and characterization of activated carbons from winemaking wastes and their adsorption of methylene blue. Adsorpt. Sci. Technol. 2018, 36, 1331-1351. [CrossRef]

13. Alguacil, F.; Alcaraz, L.; García-Díaz, I.; López, F. Removal of $\mathrm{Pb}^{2+}$ in Wastewater via Adsorption onto an Activated Carbon Produced from Winemaking Waste. Metals 2018, 8, 697. [CrossRef]

14. Bohli, T.; Ouederni, A.; Fiol, N.; Villaescusa, I. Evaluation of an activated carbon from olive stones used as an adsorbent for heavy metal removal from aqueous phases. C. R. Chim. 2015, 18, 88-99. [CrossRef]

15. Alslaibi, T.M.; Abustan, I.; Ahmad, M.A.; Abu Foul, A. Preparation of Activated Carbon from Olive Stone Waste: Optimization Study on the Removal of $\mathrm{Cu}^{2+}, \mathrm{Cd}^{2+}, \mathrm{Ni}^{2+}, \mathrm{Pb}^{2+}, \mathrm{Fe}^{2+}$, and $\mathrm{Zn}^{2+}$ from Aqueous Solution Using Response Surface Methodology. J. Dispers. Sci. Technol. 2014, 35, 913-925. [CrossRef]

16. Aljeboree, A.M.; Alshirifi, A.N.; Alkaim, A.F. Kinetics and equilibrium study for the adsorption of textile dyes on coconut shell activated carbon. Arab. J. Chem. 2017, 10, S3381-S3393. [CrossRef]

17. Lagergren, S. Zur Theorie der sogenannten Adsorption gelöster Stoffe. Handlingar 1898, 24, 1-39.

18. Ho, Y.; McKay, G. Pseudo-second order model for sorption processes. Process Biochem. 1999, 34, 451-465. [CrossRef]

19. Fouodjouo, M.; Fotouo-Nkaffo, H.; Laminsi, S.; Cassini, F.A.; de Brito-Benetoli, L.O.; Debacher, N.A. Adsorption of copper (II) onto cameroonian clay modified by non-thermal plasma: Characterization, chemical equilibrium and thermodynamic studies. Appl. Clay Sci. 2017, 142, 136-144. [CrossRef]

20. Sing, K.S.W. Reporting physisorption data for gas/solid systems with special reference to the determination of surface area and porosity (Recommendations 1984). Pure Appl. Chem. 1985, 57, 603-619. [CrossRef]

21. Williams, P.T.; Reed, A.R. Development of activated carbon pore structure via physical and chemical activation of biomass fibre waste. Biomass Bioenergy 2006, 30, 144-152. [CrossRef]

22. Shimodaira, N.; Masui, A.; Takada, A.; Tomita, N. Structural Information from the Raman Spectra of Activated Carbon Materials; Carbon: New York, NY, USA, 2000.

23. Sfyris, D.; Sfyris, G.I.; Galiotis, C. Stress intrepretation of graphene E-2g and A-1g vibrational modes: Theoretical analysis. arXiv 2017, arXiv:1706.04465.

24. Wei, Z.; Pan, R.; Hou, Y.; Yang, Y.; Liu, Y. Graphene-supported Pd catalyst for highly selective hydrogenation of resorcinol to 1, 3-cyclohexanedione through giant $\pi$-conjugate interactions. Sci. Rep. 2015, 5, 15664 . [CrossRef] [PubMed]

25. Ettehadi Gargari, J.; Sid Kalal, H.; Shakeri, A.; Khanchi, A. Synthesis and characterization of Silica/polyvinyl imidazole/H2PO4-core-shell nanoparticles as recyclable adsorbent for efficient scavenging of Sm(III) and Dy(III) from water. J. Colloid Interface Sci. 2017, 505, 745-755. [CrossRef] [PubMed]

26. Qadeer, R.; Hanif, J. Adsorption of dysprosium ions on activated charcoal from aqueous solutions. Carbon 1995, 33, 215-220. [CrossRef]

27. Boparai, H.K.; Joseph, M.; O'Carroll, D.M. Kinetics and thermodynamics of cadmium ion removal by adsorption onto nano zerovalent iron particles. J. Hazard. Mater. 2011, 186, 458-465. [CrossRef]

28. Koochaki-Mohammadpour, S.M.A.; Torab-Mostaedi, M.; Talebizadeh-Rafsanjani, A.; Naderi-Behdani, F. Adsorption Isotherm, Kinetic, Thermodynamic, and Desorption Studies of Lanthanum and Dysprosium on Oxidized Multiwalled Carbon Nanotubes. J. Dispers. Sci. Technol. 2014, 35, 244-254. [CrossRef]

29. Ghaedi, M.; Nasab, A.G.; Khodadoust, S.; Sahraei, R.; Daneshfar, A. Characterization of zinc oxide nanorods loaded on activated carbon as cheap and efficient adsorbent for removal of methylene blue. J. Ind. Eng. Chem. 2015, 21, 986-993. [CrossRef]

30. Barreca, D.; Gasparotto, A.; Milanov, A.; Tondello, E.; Devi, A.; Fischer, R.A. Nanostructured $\mathrm{Dy}_{2} \mathrm{O}_{3}$ films: An XPS Investigation. Surf. Sci. Spectra 2007, 14, 52-59. [CrossRef]

31. Chemingui, S.; Ferhi, M.; Horchani-Naifer, K.; Férid, M. Synthesis and luminescence characteristics of Dy ${ }^{3+}$ doped $\mathrm{KLa}\left(\mathrm{PO}_{3}\right)_{4}$. J. Lumin. 2015, 166, 82-87. [CrossRef] 
32. Grobelna, B.; Synak, A.; Bojarski, P.; Szczodrowski, K.; Kukliński, B.; Raut, S.; Gryczyński, I. Synthesis and luminescence characteristics of $\mathrm{Dy}^{3+}$ ions in silica xerogels doped with $\operatorname{Ln}_{2-\mathrm{x}} \mathrm{Dy}_{\mathrm{x}}\left(\mathrm{WO}_{4}\right)_{3}$. Opt. Mater. 2013, 35, 456-461. [CrossRef]

33. Alcaraz, L.; Isasi, J.; Díaz-Guerra, C. Influence of the synthesis conditions of $\mathrm{Y}_{0.9} \mathrm{Dy}_{0.1} \mathrm{VO}_{4}$ and silica-coated $\mathrm{Y}_{0.9} \mathrm{Dy}_{0.1} \mathrm{VO}_{4}$ nanophosphors on the powder morphology and luminescence emission intensity. J. Nanopart. Res. 2019, 21, 81. [CrossRef]

34. Grobelna, B.; Synak, A.; Bojarski, P. The luminescence properties of dysprosium ions in silica xerogel doped with $\mathrm{Gd}_{1.6} \mathrm{Dy}_{0.4}\left(\mathrm{WO}_{4}\right)_{3}$. Opt. Appl. 2012, 42, 337-344.

(C) 2019 by the authors. Licensee MDPI, Basel, Switzerland. This article is an open access article distributed under the terms and conditions of the Creative Commons Attribution (CC BY) license (http://creativecommons.org/licenses/by/4.0/). 